\title{
Adoção de inovações de processos em período de crise pelas empresas de Petrolina-PE
}

\author{
Guilherme Alves de Doutorando em Ciência da Informação. Universidade Federal de Pernambuco \\ Santana (UFPE) - Brasil. guilherme.alves.santana@gmail.com \\ Fabio Mascarenhas e Doutor em Ciência da Informação. Universidade de São Paulo (USP) - Brasil. \\ Silva fabiomascarenhas@gmail.com \\ Ednaldo Jose de Alencar Especialista em Gestão Financeira e Consultoria Empresarial. Universidade \\ e Silva Regional do Cariri (URCA) - Brasil. e.djsazoog@hotmail.com \\ Lúcia Alves Domingos Bacharel em Administração. Faculdade de Ciências Aplicadas e Sociais de \\ Petrolina (FACAPE) - Brasil. luciaalvesconsult@gmail.com
}

\section{RESUMO}

Este artigo objetiva mapear quais inovações de processos foram implementadas por Micro e Pequenas Empresas (MPEs) de Petrolina, localizadas em Petrolina (Sertão do São Francisco, Pernambuco). Para tanto, esta pesquisa é de natureza básica e exploratória, tendo se baseado em procedimentos bibliográficos e documentais para o levantamento de dados. Ainda foi realizada uma pesquisa de campo em empresas no setor de serviços. O método utilizado foi o quantitativo e os dados foram coletados através da aplicação de questionários focados em inovação e gestão, presencialmente com vinte empresários de diferentes segmentos da região. Os resultados indicam que as ações de inovação executadas nas MPEs contribuíram para superar efeitos da crise político-econômica do período 2015 a 2017. Tais inovações focaram em ações de benchmarking, reestruturação de departamentos, capacitação dos colaboradores, criação de estratégias para venda de produtos, mapeamento dos processos, redução na quantidade de fornecedores, aumento do quadro funcional, melhoria do layout da empresa, terceirização do serviço de entrega, registro de desperdícios, aquisição de softwares gerenciais, gestão eletrônica de documentos e adequação aos aspectos ecológicos. Além disto, a pesquisa in loco possibilitou observar que os empresários possuem uma visão imediatista e uma fragilização dos processos de construção de uma cultura da inovação.

Palavras-chave: Inovação. Processos. Radar da Inovação.

\section{Adoption of innovation processes in a period of crisis by the companies of Petrolina-PE}

\begin{abstract}
This article aims to map the processes of innovation implemented by Micro and Small Businesses (MPEs) in Petrolina in the State of Pernambuco. This research is of a basic and exploratory nature, based on bibliographic and documentary procedures for data collection. A field research was also carried out in companies in the service sector. The method used was quantitative and data were collected through questionnaires focused on innovation and management, and applied to twenty businessmen from different segments of the region, in person. The results indicate that the innovation actions implemented in the SMEs contributed to overcome the effects of the political and economic crisis of the period from 2015 to 2017. These innovations focused on
\end{abstract}


benchmarking, department restructuring, employee training, creation of strategies for selling products, mapping of processes, reduction in the number of suppliers, increase of staff, improvement of the layout of the company, outsourcing of delivery service, waste registration, acquisition of management software, electronic document management and adaptation to ecological aspects. In addition, on-site research made it possible to observe that entrepreneurs have a vision based on immediacy and frailty in the processes of building a culture of innovation.

Keywords: Innovation. Processes. Radar of Innovation.

\section{INTRODUÇÃO}

A crise político-econômica que se deflagrou no Brasil em meados de 2015 gerou desemprego, queda no faturamento e fechamento de empresas, bem como mudanças nas ações dos empresários. Alguns destes demonstraram descontentamento e estagnação por conta do cenário econômico caótico, mas também houve casos onde gestores realizaram mudanças para superar a recessão econômica. Estes reinventaram suas organizações, adotando novas estratégias e executando planos de ações mais adequados à nova realidade de mercado (MATTEI; RUCINSKI, 2016; POZOBON; PRATES, 2016).

De acordo com Bauer (1999), há muita complexidade nas organizações e é comum existirem processos de reorganização em meio ao caos. Partindo desta assertiva, Bezerra (2010) argumenta que as empresas devem aproveitar momentos turbulentos para prover mudanças, adotando novas estratégias para captar clientes e mercados. Para o autor, um olhar diferenciado, a ponto de identificar novas possibilidades, em momentos de crise parece ser um diferencial para a sobrevivência ou mesmo crescimento de suas empresas.

Neste sentido, inovar pode ser uma ação para a empresa sair de um cenário instável e mudar de patamar. Sobre esta assertiva, Pradella (2013) destaca a importância da inovação para a gestão organizacional, uma vez que empresas que desejem diferenciar-se das concorrentes por meio da inovação tendem a buscar mais qualidade, flexibilidade, redução no tempo de produção, bem como obter maior eficiência e, consequentemente, maior lucro.

Os benefícios do desenvolvimento de ações inovadoras nas atividades empresariais (rotinas, procedimentos e tarefas), levando em consideração que o constante aprimoramento dos processos pode gerar contribuições para a organização, sobretudo na redução de custo e aumento da produtividade (PRADELLA, 2013; MOMPEAN, 2014).

Para Roman et al (2012), a impossibilidade de fazer reajustes nos preços dos produtos, levam muitas empresas a optar pelo desenvolvimento de novas direções estratégicas para a execução das atividades, modificando o processo produtivo. Pradella (2013) acrescenta que essas atividades nem sempre acarretam em grandes investimentos para as empresas, pois podem gerar criação de novos produtos e serviços (ações, informações e métodos), melhoria nos procedimentos para realização de uma venda, ajustes na linha de produção, manutenção preventiva dos bens, dentre outros. Portanto, a inserção de inovações de processos pode representar uma saída para a crise nas empresas brasileiras.

Devido ao foco dado neste estudo, será analisada a atuação de Micro e Pequenas Empresas (MPEs) da cidade de Petrolina (sertão do São Francisco do Estado de Pernambuco) que vivenciou momentos de recessão. Segundo o Governo do Estado de Pernambuco (2017), por mais que a localidade tenha se destacado pelo turismo e pela produção e exportações de vinho e uva, sentiu efeitos negativos no setor de serviços, que pôde ser notado pela redução dos preços finais, com reflexo negativo nas margens de lucro das empresas do segmento.

Por conta da crise, gestores das empresas da região desenvolveram novas estratégias para superar as dificuldades deste período. Neste contexto, este artigo visa mapear quais as inovações de processos foram implementadas por uma amostra de $20 \mathrm{MPEs}$ localizadas em Petrolina-PE. Para atingir este objetivo, este trabalho inicialmente apresentará o cenário que se instalou no Brasil por conta da crise político-econômica de 2015, e quais as contribuições da inovação para as MPES, sobretudo, as inovações de processos. Em seguida, relatam-se os procedimentos metodológicos. Por fim, discutem-se os resultados obtidos com a pesquisa de campo e são apresentadas as considerações sobre a pesquisa. 


\section{REVISÃO DE LITERATURA}

Neste capítulo, discutir-se-á crise/recessão econômica no Brasil e como a inovação pode auxiliar MPEs a superá-la. Além disto, será apresentada uma discussão sobre inovação. Por fim, o destaque é dado para as inovações de processos e como estas podem contribuir para as MPEs, essencialmente em períodos de crise econômica.

\subsection{A crise política econômica no Brasil de 2015}

Conforme Struck (2016), as instabilidades políticas, diminuição dos investimentos na economia, redução do consumo interno, necessidades de reformas tributárias e problemas de corrupção em estatais, foram os principais fatores para desencadear uma crise política econômica no Brasil em meados de 2015. Pozabon e Prates (2016) apontam que a crise trouxe efeitos negativos no cenário econômico, aumentando o índice do desemprego, impactando na diminuição do Produto Interno Bruto (PIB).

Struck (2016) ainda acrescenta que a redução no PIB no ano de 2015 foi de 3,8\%, sendo um dos piores resultados desde que o índice começou a ser divulgado (em 1996), e de 4,6\%, com relação a 2014, chegando a 5,9 trilhões de reais. De acordo com o Instituto Brasileiro de Geografia Estatística (INSTITUTO BRASILEIRO DE GEOGRAFIA E ESTATÍSTICA, 2017), o desemprego aumentou, indo de patamares de 6,5\% (em 2014) para 8,9\% (em 2015). Os desdobramentos negativos dessa crise em 2016 ainda eram evidentes, uma vez que o PIB continuava reduzindo, registrando queda de 3,6\%, e o índice de desemprego aumentando, fechando em 11,5\%, correspondendo a 12,3 milhões de pessoas desempregadas (INSTITUTO BRASILEIRO DE GEOGRAFIA E ESTATÍSTICA, 2017).

Para Leite (2010), o maior número de pessoas sem trabalho impacta no índice de inadimplência, diminuindo o consumo e forçando a retração da produção nas empresas, levando a uma subsequente redução de faturamento. Esta reação em cadeia levou as empresas brasileiras a manter suas operações com baixas taxas de lucro, operar com margens negativas (utilizando o capital acumulado em períodos anteriores), fazer empréstimos ou deixar de operar. Esta última opção passou a ser uma realidade bastante comum, pois no período de estagnação da economia nacional houve um elevado índice de mortalidade empresarial (aproximadamente 10\%) em 2015 e em 2016 (FERNANDES, 2016).

No estado de Pernambuco, o setor de serviços foi abalado com os desdobramentos dessa crise e teve uma variação negativa em 2016, com relação ao ano anterior (FERNANDES, 2016). A Governo do Estado de Pernambuco (2017) descreveu, por exemplo, que no interior de Pernambuco (por exemplo, na região do São Francisco), os efeitos negativos nos setores de comércio e serviços contribuíram diretamente para a redução da margem de lucro das empresas, que em sua maioria eram formadas por MPEs. No que tange esse cenário caótico nas empresas da Região do São Francisco, Fernandes (2016) destacou que mudanças no comportamento empreendedor eram fundamentais para reverter ou minimizar esses resultados negativos. $O$ autor ainda acrescentou que tais mudanças precisavam vir do surgimento de novas estratégias que envolvessem todo o tipo de recurso disponível na empresa e identificou casos de empresários que utilizaram a inovação como ativo essencial para o desenvolvimento e continuidade de suas atividades.

\subsection{As Contribuições da Inovação de Processos para as MPEs}

A sociedade hoje é formada por organizações dinâmicas, que mudam constantemente e que devem atender ao surgimento de novas necessidades dos consumidores (SOUZA; BARROS NETO, 2012). Logo, a inovação pode ser considerada uma ferramenta estratégica, que se utilizada coerentemente, pode levar as organizações a se tornarem mais competitivas, propiciar que novas ideias sejam introduzidas e identificar novos mercados (PIERRY, 2001; REINA, 2015).

Maxamadumarovich, Obrenovic e Amonboyev (2012) acrescentam sua contribuição nessa discussão ao afirmarem que a inovação integra a modernidade gerencial e que tem sido utilizada em diferentes perspectivas e pontos de vista por atores sociais, empresariais e governamentais. Os autores ainda diferenciam 
três tipos de inovação no nível da empresa a partir da perspectiva de tecnologia e modelo de negócio, a saber: inovações incrementais são singelas melhorias e aprimoramentos; semi-radicais são inovações explicadas por sutis alterações na tecnologia ou modelo comercial da empresa; e radicais são mudanças revolucionárias para produtos e processos de negócios existentes.

A inovação pode ocorrer por meio da habilidade de fazer relações, enxergar oportunidades e aproveitálas, de modo que novos mercados possam ser identificados ou impulsionados (BESSANT; TIDD, 2009). Assim, ser inovador não exige apenas a abertura de novos mercados, mas também a capacidade de atender às expectativas daqueles já existentes e amadurecidos. Vale salientar que para atender o processo de inovação, recursos técnicos e competências gerenciais são necessários.

No que se refere ao conjunto de características que distingue os profissionais inovadores, Dyer, Gregersen e Christensen (2011) apontam que a habilidade de gerar novas ideias não é mera função da capacidade cerebral, visto que advém também do desenvolvimento de alguns comportamentos. Segundo os autores, as cinco competências comuns na descoberta de inovações são: questionar; observar; trabalhar em rede; experimentar; e associar. Estas competêncais cumprem um papel importante nas fases iniciais do processo de inovação e quando utilizadas de forma sistemática aumentam a capacidade empresarial de gerar novas ideias e executá-las.

Logo, as empresas que criam novos mercados e variações organizacionais podem ser consideradas inovadoras (SPEZAMIGLIO; GALINA; CALIA, 2016). Rosa (2015) acrescenta que a inovação não deve ser vista como um evento isolado, mas sim como um processo sistemático, por depender de várias atividades em todos os níveis das organizações.

Para Schumpeter (1984), as organizações inovadoras se adaptam com mais facilidade ao ambiente externo conturbado; o que lhes permite reagir mais rapidamente e de forma mais efetiva evitando riscos e captando oportunidades mercadológicas. Os autores ainda acrescentam que a inovação mercadológica pode auxiliar a criar novos nichos de mercados, reinventado os existentes para se adaptar as reais necessidades da sociedade onde estão inseridos.

Oliveira et al (2016) descrevem o conceito de inovação pautado no desenvolvimento tecnológico, ampliando os horizontes nas MPEs para o surgimento de novos produtos ou serviços, novos processos e novos métodos de produção. Neste sentido, Botelho, Carrigo e Kamasaki (2007) defendem a ideia de que a localização em proximidade das empresas com as instituições de pesquisa e desenvolvimento tornam a atividade inovadora mais fácil nas MPEs. Cruz (2003) corrobora ao considerar que a flexibilidade em se adaptar às mudanças mercadológicas é um fator que impulsiona a atividade inovação em uma MPE.

Embora haja uma diversidade conceitual, os estudiosos de inovação apontam que uma organização inovadora possui a habilidade de criar valor para o cliente (KNOX, 2002; MACHADO; CARVALHO, 2013). Tal postura propicia à empresa um diferencial em relação a seus concorrentes, facilitando o alcance de uma posição de destaque no mercado. Levando em consideração os benefícios que a inovação pode gerar para as MPEs, vale ressaltar que a mesma pode ocorrer por meio de aperfeiçoamentos ou surgimentos de produtos (bem ou serviço), métodos de marketing, métodos organizacionais, considerando as relações internas e externas, bem como um novo processo ou antigo processo modificado para melhor (ORGANISATION FOR ECONOMIC COOPERATION AND DEVELOPMENT, 2005).

Sobre a inovação de processos, observa-se que pode ser concebida através da introdução de novos materiais ou procedimentos da cadeia produtiva até o consumidor final, ou ainda a melhoria dos mesmos (OLIVEIRA et al, 2016). Nesse contexto, segundo o que já foi exposto, implementar uma inovação de processos não necessita de grandes investimentos de uma MPE, devido aos próprios empresários terem a capacidade de aprimorar procedimentos, metodologias e rotinas não eficientes ou eficazes, gerando reduções de custo e aumento de produtividade.

São os processos de negócio que geram os produtos e serviços oferecidos pelas empresas, e cada processo deve ser voltado ao atendimento das necessidades e expectativas dos clientes. Processos bem definidos podem auxiliar o relacionamento de empresas com clientes e fornecedores, identificando expectativas, prevenindo problemas e apoiando no controle das finanças da organização de várias maneiras (MOMPEAN, 2014). Os métodos, ações, informações e quaisquer atividades desenvolvidas dentro da empresa 
no objetivo de contribuir para o desenvolvimento de um bem ou serviço é considerado um processo (BACHMANN; DESTEFANI, 2008).

Desta maneira, uma inovação de processos pode ser o aperfeiçoamento dos materiais e procedimentos, e quando diretamente relacionada com os avanços tecnológicos, pode impulsionar a eficiência da empresa, resultando em redução dos desperdícios e consequente, aumento da margem de lucro (MOMPEAN, 2014). A Organisation For Economic Co-Operation And Development (2005) aponta que o desenvolvimento de novas estratégias para aplicabilidade de todas as atividades que envolvem o negócio da empresa (e que possibilitem o aumento da competitividade) pode ser considerado inovação de processos. Essas inovações contribuem para o aumento da qualidade, flexibilidade nas operações, diminuição dos custos, redução no tempo de produção ou execução dos serviços nas MPEs.

Teixeira et al (2014) descreve que a inovação de processos é fundamental para criar uma competitividade mais acirrada, bem como ofertar benefícios em curto, médio ou longo prazo às empresas. Oliveira et al (2016) vêem a inovação de processos interligada com a gestão dos processos, pois o ciclo de atividades e rotinas deve ser gerenciado de forma continuada, agregando valor e contribuindo para o aprendizado sobre o aperfeiçoamento dos processos que são executados diariamente nas empresas. Vale ressaltar que diversas empresas apresentam potencial de crescimento no início de suas operações, por tomarem conceitos metodológicos de gestão de processos e inovação como base. No entanto, é necessário manter o controle e estabelecer um alicerce concreto para o futuro, levando em consideração aspectos internos e externos (ORGANISATION FOR ECONOMIC CO-OPERATION AND DEVELOPMENT, 2005).

Scherer e Carlomagno (2016) indicam que a inovação não deve ser um processo solto, criado no vácuo. Ela necessita de um planejamento prévio e um ambiente organizacional estruturado, que propicie a implementação de novas ideias e métodos de trabalho.

Oliveira et al (2016) ainda adicionam que quando a empresa começa a pensar em inovar nos seus processos, é necessário difundir a ideia entre seus funcionários, pois os mesmos representam o caminho para desenvolver a ideia com sucesso. São os colaboradores que desenvolvem as atividades, então, só eles podem apresentar sugestões eficientes dentro de cada atividade que executam. O autor ainda complementa que com a implantação das inovações, vão surgir novas tarefas e responsabilidades que poderão ser atribuídas aos funcionários, e dessa forma requer uma maior gestão dos processos. Alguns exemplos de inovações de processos, segundo Bachmann e Destefani, (2008) podem ser: mudança de forma planejada no layout ou arranjo físico do negócio; busca por uma melhor localização dos produtos ou máquinas; reformas na climatização ou iluminação, produtos de alta tecnologia que auxiliem nos processos, como softwares de gestão, como também técnicas de controle de resíduos e matéria-prima.

\section{PROCEDIMENTOS METODOLÓGICOS}

O método e abordagem para o desenvolvimento do referido trabalho foi o quantitativo, que segundo Cervi (2009) busca por meio de métodos estruturados, como questionários, entrevistas, técnicas de estatística, como média, porcentagem, desvio padrão, entre outros, alcançar resultados com alto grau de confiabilidade. Minayo (2010) acrescenta que o método quantitativo é bastante usado em pesquisa de campo no cunho social, mercadológico, administrativo e econômico, pois são representados de forma mais concreta, garantindo a exatidão dos resultados.

Já em relação à natureza, esta pesquisa é básica, pois gerou conhecimentos novos, úteis à compreensão do comportamento da dinâmica da inovação em empresas do Sertão de Pernambuco, proporcionando maior familiaridade com uma temática ainda pouco explorada (GIL, 2008). Sendo assim, esta pesquisa é exploratória, já que é um trabalho que possibilita a comunidade científica familiarizar-se com o assunto, formular novas hipóteses ou desenvolver novos questionamentos em busca de ampliar o conhecimento (GIL, 2008). É bibliográfica, quanto aos procedimentos, devido à exploração das principais bases teóricas contidas em publicações científicas diversas (GIL, 2008). Além disto, é documental, tendo relatórios técnicos como fonte de informação primária. 
A pesquisa de campo se deu através da aplicação de questionários compostos por perguntas abertas, realizadas diretamente a 20 empresários da Região do Sertão do São Francisco, e especificamente, da cidade de Petrolina-PE. A amostra é composta por MPEs do setor de serviços que participaram da terceira edição do Programa Agentes Locais de Inovação (ALI), operacionalizado a partir de uma cooperação técnica entre o Conselho Nacional de Desenvolvimento Científico e Tecnológico (CNPq) e o Serviço Brasileiro de Apoio às Micro e Pequenas Empresas (SEBRAE).

Para o questionário e coleta de dados, foi utilizada uma ferramenta metodológica denominada de Radar da Inovação, desenvolvida pelo Professor Mohanbir Sawhney, diretor do Center for Research in Technology \& Innovation, da Kellog School of Management, em Illinois - EUA (BACHMANN; DESTEFANI, 2008). O Radar da Inovação é um diagnóstico que possui 13 variáveis de análise, com perguntas específicas que avaliam o grau de inovação de empresas brasileiras de micro e pequeno porte. Cada variável busca mapear pontos fortes e fracos que a empresa possui e identificar ações de inovação implementadas nas empresas, a fim de averiguar se a empresa obteve aumento da produtividade, se criou conhecimento organizacional, reduziu custos e otimizou recursos.

Dentre os aspectos analisados no radar, a variável processos chama a atenção por estar presente como um tipo de inovação que pode gera impactos significativos em empresas (SCHUMPETER, 1984; ORGANISATION FOR ECONOMIC CO-OPERATION AND DEVELOPMENT, 2006). Tal variável avalia as configurações das atividades usadas na condução das operações internas da empresa, a fim de criar um produto ou prestar um serviço (BACHMANN; DESTEFANI, 2008). Por este motivo, a mesma será analisada especificamente neste trabalho, visto que as inovações de processos podem gerar resultados para as MPEs. Assim como todas as demais variáveis do radar, a variável processos possui itens, ou subdivisões que são apresentadas no Quadro 1.

Quadro 1 - Descrição dos itens da variável Processos do Radar da Inovação.

\begin{tabular}{|c|c|}
\hline ITENS & DESCRIÇÃO \\
\hline $\begin{array}{l}\text { Melhoria dos } \\
\text { processos }\end{array}$ & $\begin{array}{l}\text { Modificação dos processos e rotinas da empresa, compras ou aluguel de equipamentos } \\
\text { diferentes dos usados anteriormente, adoção de técnicas de gestão de produção mais } \\
\text { modernas, para obter maior eficiência, qualidade, flexibilidade ou menor ciclo de } \\
\text { produção. }\end{array}$ \\
\hline $\begin{array}{l}\text { Sistemas de } \\
\text { gestão }\end{array}$ & Adoção de novas práticas de gestão. \\
\hline Certificações & Conquista de nova certificação de processo ou de produto. \\
\hline $\begin{array}{l}\text { Softwares } \\
\text { gestão }\end{array}$ & $\begin{array}{l}\text { Adoção de algum novo software para a gestão administrativa ou da produção com o } \\
\text { propósito específico de ganhar diferenciação. }\end{array}$ \\
\hline $\begin{array}{l}\text { Aspectos } \\
\text { ambientais } \\
\text { (Ecológicos) }\end{array}$ & Modificação de insumo ou processo por razões ecológicas. \\
\hline Gestão de resíduos & Transformação de parte de seus resíduos em uma oportunidade de gerar receita. \\
\hline
\end{tabular}

No diagnóstico Radar da Inovação, as respostas dos itens são obtidas através de perguntas abertas, uma vez que os entrevistados devem informar alguma evidência que ateste o que está sendo dito. Por exemplo, na variável Processos, o item Sistemas de Gestão é avaliado a partir da seguinte pergunta: Nos últimos três anos, a empresa adotou pelo menos duas novas práticas de gestão? As respostas obtidas geram evidências ou justificativas para definir os escores (ou pontuação) dentro de cada variável. Tais escores costumam variar de 1 a 5, sendo atribuído escore 1,0 para uma organização pouco inovadora, escore 3,0 para uma organização inovadora ocasional e o escore 5,0 para a organização inovadora sistêmica (BACHMANN; DESTEFANI, 2008). No caso das vinte empresas analisadas, o Radar da Inovação foi aplicado entre abril de 2015 e setembro de 2017. 


\section{ANÁLISE E DISCUSSÃO DOS RESULTADOS}

Os dados obtidos na pesquisa de campo são apresentados no quadro 2, que destaca os resultados mais baixos em vermelho, os resultados das empresas com inovações ocasionais em amarelo e as melhores pontuações em verde.

Conforme visto no quadro 2, apenas cinco empresas ( $25 \%$ da amostra) apresentaram grau médio de inovação igual ou superior a 3,0, demonstrando que as empresas analisadas carecem no quesito processos.

Quadro 2 - Grau de inovação de processos das EPPs do sertão de Pernambuco.

\begin{tabular}{|c|c|c|c|c|c|c|c|}
\hline Empresa & $\begin{array}{l}\text { Melhoria } \\
\text { dos } \\
\text { processos }\end{array}$ & $\begin{array}{l}\text { Sistemas } \\
\text { de gestão }\end{array}$ & Certificações & $\begin{array}{l}\text { Softwares } \\
\text { de gestão }\end{array}$ & $\begin{array}{c}\text { Aspectos } \\
\text { ambientais } \\
\text { (Ecológicos) }\end{array}$ & $\begin{array}{l}\text { Gestão } \\
\text { de } \\
\text { resíduos }\end{array}$ & $\begin{array}{l}\text { Grau Médio } \\
\text { de Inovação }\end{array}$ \\
\hline Emp1 & 5,0 & 5,0 & 1,0 & 5,0 & 5,0 & 5,0 & 4,3 \\
\hline Emp2 & 5,0 & 5,0 & 1,0 & 3,0 & 3,0 & 1,0 & 3,0 \\
\hline Emp3 & 3,0 & 1,0 & 1,0 & 1,0 & 1,0 & 3,0 & 1,7 \\
\hline Emp4 & 5,0 & 1,0 & 1,0 & 3,0 & 5,0 & 3,0 & 3,0 \\
\hline Emp5 & 3,0 & 3,0 & 1,0 & 1,0 & 1,0 & 1,0 & 1,7 \\
\hline Emp6 & 5,0 & 5,0 & 1,0 & 1,0 & 3,0 & 3,0 & 3,0 \\
\hline Emp7 & 1,0 & 3,0 & 1,0 & 3,0 & 1,0 & 1,0 & 1,7 \\
\hline Emp8 & 1,0 & 1,0 & 1,0 & 1,0 & 1,0 & 3,0 & 1,3 \\
\hline Empg & 3,0 & 3,0 & 1,0 & 3,0 & 1,0 & 1,0 & 2,0 \\
\hline Emp10 & 1,0 & 3,0 & 1,0 & 3,0 & 1,0 & 1,0 & 1,7 \\
\hline Emp11 & 3,0 & 3,0 & 1,0 & 1,0 & 1,0 & 1,0 & 1,7 \\
\hline Emp12 & 3,0 & 1,0 & 1,0 & 5,0 & 1,0 & 1,0 & 2,0 \\
\hline Emp13 & 3,0 & 1,0 & 1,0 & 1,0 & 1,0 & 1,0 & 1,3 \\
\hline Emp14 & 3,0 & 1,0 & 1,0 & 3,0 & 1,0 & 1,0 & 1,7 \\
\hline Emp15 & 3,0 & 1,0 & 1,0 & 1,0 & 1,0 & 1,0 & 1,3 \\
\hline Emp16 & 1,0 & 3,0 & 1,0 & 1,0 & 1,0 & 1,0 & 1,3 \\
\hline Emp17 & 3,0 & 3,0 & 1,0 & 1,0 & 1,0 & 1,0 & 1,7 \\
\hline Emp18 & 5,0 & 5,0 & 1,0 & 5,0 & 1,0 & 5,0 & 3,6 \\
\hline Emp19 & 3,0 & 1,0 & 1,0 & 1,0 & 1,0 & 1,0 & 1,3 \\
\hline Emp2o & 3,0 & 3,0 & 1,0 & 1,0 & 1,0 & 1,0 & 1,7 \\
\hline
\end{tabular}

Fonte: Autoria própria (2015-2017).

É possível visualizar aspectos deficientes na dimensão processos, como o item 'certificações' (que teve média 1,0), o item 'aspectos ambientais' (média 1,6). Por outro lado, houve itens com médias melhores, como o item 'melhoria de processos' (média 3,1) e 'sistemas de gestão' (com 2,6). No gráfico 1 esta deficiênca é melhor visualizada.

Gráfico 1 - Média das Empresas na variável Processos. 


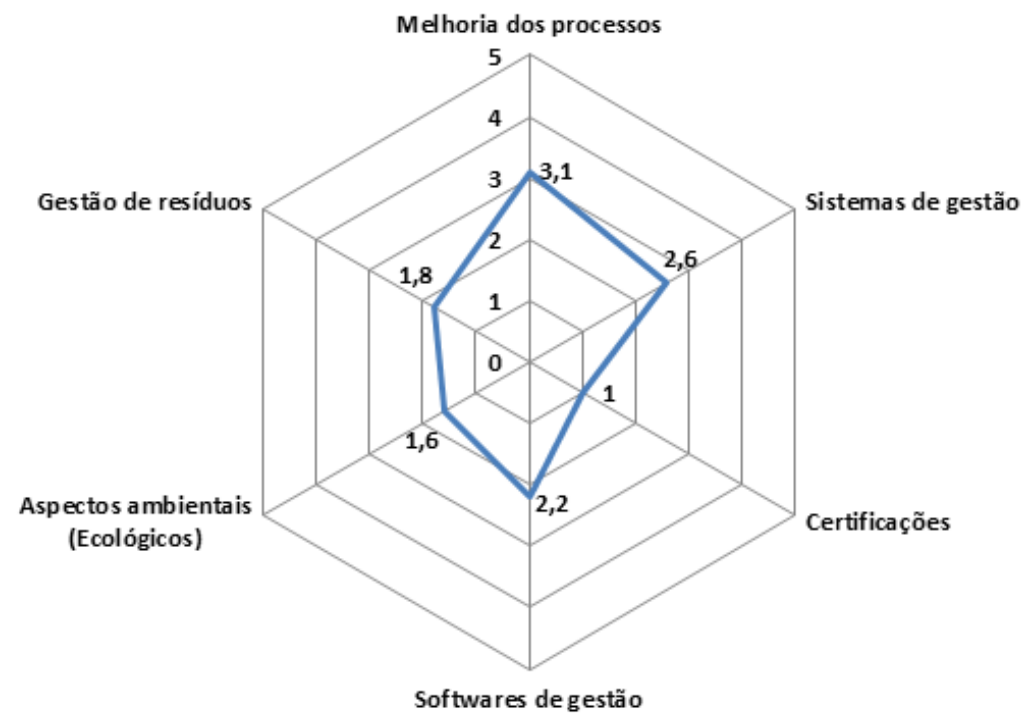

Fonte: Autoria própria (2015-2017).

A respeito do item Melhoria dos processos, apenas cinco (25\% das empresas) das empresas, obtiveram o escore máximo (5), demonstrando que poucas das organizações analisadas costumam aperfeiçoar seus processos. A emp1, por exemplo, reajustou sua maneira de gerenciamento de estoque, e neste processo aperfeiçoou a forma de gestão, reduzindo também o seu estoque. Segundo o entrevistado da emp1, foi possível compreender que um estoque mais enxuto seria mais adequado para obter finanças mais equilibradas, e que a melhoria nesta área veio após capacitação dos colaboradores e padronização dos processos do setor de estoque.

Por outro lado, o entrevistado da emp2 argumentou que os principais resultados com os processos surgiram quando a empresa passou por uma reestruturação no departamento de marketing, que acarretou em um melhor aproveitamento dos investimentos com publicidade e propaganda, e subsequente redução de custos. Os impactos dessas mudanças deram subsídios para uma reestruturação de toda a organização.

Para melhorar os processos organizacionais, a emp4 realizou uma capacitação dos colaboradores na área de estoque e atendimento. Esta ação se desdobrou na etiquetagem de todos os produtos e agrupamento de clientes para facilitar o atendimento e vendas. Já a emp6 participou de um curso de Ferramentas de Gestão Avançadas e mapeou e documentou todos os seus processos. Segundo o mesmo entrevistado, a documentação dos processos permitiu um acompanhamento em tempo real da estocagem e giro de produtos de forma mais efetiva.

A emp18 também mapeou seus processos, obtendo redução das despesas com compras e passando a trabalhar com produtos de maior rotatividade. Foram criadas estratégias para vender os produtos que estavam há muito tempo no estoque. Ainda vale ressaltar que o mapeamento dos processos gerou aprendizado organizacional, uma vez que a empresa passou a incentivar que os colaboradores sugerissem novos produtos a serem comprados com base no conhecimento do seu setor. Esta ação possibilitou otimização no uso dos recursos da empresa.

Por outro lado, 11 empresas demonstraram buscar a melhoria de processos ocasionalmente, revelando que necessitam aprimorar seus processos para obter melhores controles e de inovações sistemáticas. As empresas com algum tipo de ação ocasional foram: emp3, devido ter promovido uma mudança de horário dos colaboradores para melhor atender aos clientes e uma substituição de uma transportadora a fim de reduzir seus custos logísticos; emp5, que promoveu uma redução na quantidade de fornecedores e de estoque da empresa, melhorando também o seu processo de compras; a empg realizou uma mudança nas instalações para proporcionar maior conforto e qualidade na prestação dos serviços ao cliente; já a inovação de processo ocasional da empı1 foi à melhoria do atendimento e rapidez na prestação do serviço; com a aquisição de um software de gestão, voltado para o segmento de seguros, a emp12 obteve maior agilidade em seus processos; a emp13 ampliou a estrutura física com a construção de quatro salas, aumentando também seu quadro funcional (profissionais de saúde e recepcionistas); a emp14 realizou uma reforma significativa na estrutura física para 
buscar um melhor layout na loja; a emp17 melhorou a forma de armazenamento dos produtos, que anteriormente ficavam em caixas, comprometendo o visual do estabelecimento; a emp19 modificou a forma de entrega dos produtos por questões logísticas; e a emp2o cumpriu exigências legais e instalou o cupom fiscal. Por fim, quatro empresas não realizaram nenhuma inovação de melhoria de processo.

No que diz respeito ao item sistemas de gestão, identificou-se que quatro empresas alcançaram o escore máximo $(5,0)$ demonstrando capacidade de inovação em processos. A emp1 terceirizou o serviço de entrega de móveis convencionais e passou a fazer uso de benchmarking. A emp2 passou a fazer planejamento de marketing e modificou seus procedimentos de controle financeiro. Já na emp5, identificou-se a adoção do benchmarking e elaboração de um manual de boas práticas. Por fim, a emp 18 inseriu novas práticas de gestão, a exemplo do controle de perdas (passou a registrar seus desperdícios) e o benchmarking (identificação de boas práticas para implantação na empresa).

Um aspecto chamou a atenção em relação as empresas que obtiveram pontuação 3,0: oito organizações adotaram o benchmarking como ferramenta de gestão, sendo as seguintes: emp5, emp7, emp9, emp10, emp11, emp16, emp17 e emp 20. As demais oito empresas não apresentaram nenhuma evidência de existência de um sistema ou prática de gestão, e assim, infere-se que estas empesas carecem de ferramentas de gerenciamento. Desta maneira, percebe-se que o benchmarking é a ferramenta de gestão mais utilizada pelas empresas de Petrolina, o que se deve ao fato da competitividade existente no mercado e que se aflorou ainda mais com a crise. No entanto, observa-se as inovações neste item são de abrangência para a empresa, e não para o mercado.

No item Certificações, identificou-se que nenhuma das empresas avaliadas possui algum tipo de certificação. Normalmente, certifcações são exigidas ou necessárias quando a empresa é do setor industrial, mas isso não impede as empresas ou seus funcionários buscarem algum outro tipo de certificação.

Em relação aos Softwares de gestão utilizados para gerenciar os processos, averiguou-se que apenas três empresas obtiveram escore 5,0, demonstrando que as empresas analisadas não possuem o costume de adquirir softwares gerenciais por não darem importância ou não priorizarem esta ação. Das empresas com inovações sistemáticas, destaca-se a emp1 que adquiriu um software de simulação de ambientes em 3D. Já a emp12 adquiriu um sistema de gestão voltado para o segmento de seguros. A emp18 adquiriu um novo software para gerenciamento da empresa. Nesses três casos, os empresários entrevistados alegaram terem obtidos os softwares, nos últimos três anos, a fim de ganhar diferenciação frente à concorrência e ter agilidade em seus processos.

Embora algumas empresas possuam softwares de gestão, as mesmas obtiveram escore 3,0, porque não os alimentavam e, consequentemente, não tomavam decisões com as informações que poderiam ser geradas pelos mesmos. A emp2 adotou um software gerencial específico para salão de belezas, no entanto ainda não é devidamente explorado. A emp4 possuía um software de gestão de vendas de móveis. A emp7 tinha um software de gestão voltado para prestação de serviços diversos. Já a empg possuía um software de gestão para academia. Por outro lado, a emp1o utilizava um software de gestão eletrônica de documentos. Por fim, a emp14 usava um sistema de gestão apropriado para seu segmento, mas que também não tinha todas as funções exploradas.

Logo, 11 das 20 empresas analisadas destacaram que não possuem softwares de gestão e, conforme observação realizada in loco, há empresas que possuem mecanismos arcaicos de controle, chegando a registrar de punho boa parte das vendas e pagamentos realizados. Embora esta condição já seja desfavorável, há empresas que não possuem registro algum.

Para se adequar a questões ecológicas, há diversos movimentos no âmbito empresarial voltados para buscar a sustentabilidade, seja por exigências/normas ou pela preocupação ambiental. No Brasil existem programas que estimulam a diminuição ou uso indevido de recursos como água, energia, resíduos e matériasprimas. Em relação ao item aspectos ambientais (Ecológicos), somente duas empresas realizam inovações sistemáticas: a empı, por exemplo, realizou a troca de lâmpadas comuns por lâmpadas econômicas, o que segundo o empresário entrevistado, resultou na diminuição da conta de energia; a emp4 também fez adequações a aspectos ecológicos, como o uso de iluminação natural em seus ambientes, destinação dos plásticos a empresas de reciclagem, incineração das madeiras inutilizadas, reaproveitamento da água da chuva 
e do ar-condicionado para regar o jardim. Sendo assim, percebe-se que estas empresas apresentaram um ambiente de inovação de processos voltados a redução de custos e ao meio ambiente.

As empresas 2 e 5 apresentaram evidências que justificaram ser consideradas como empresas com inovação de processos ocasionais, pois não as realizaram nos últimos três anos. Segundo o entrevistado da emp2, durante a última reforma, foi realizada uma troca do tipo de ar-condicionado no intuito de reduzir o consumo de energia elétrica. Já a emp5 vem substituindo as lâmpadas tradicionais por lâmpadas de led, e durante a reforma predial, solicitou-se que o responsável do projeto criasse ambientes que pudessem aproveitar a luz natural.

Um alerta que emerge com o resultado deste item é o fato de 16 empresas não terem realizado nenhum tipo de modificação de seus processos por conta de razões ecológicas, o que aponta para o desconhecimento ou despreocupação com a destinação com alguns elementos, e com o desperdício de energia, água e matériasprimas. Há a necessidade de uma sensibilização direta de incentivos para estes empresários realizarem ações voltadas ao meio ambiente.

No que tange a gestão de resíduos, apenas a emp1 e a emp18 obtiveram escore 5,0 neste item. A primeira por ter uma política de vendas das embalagens de papelão e plásticos de seus produtos a catadores, que por sua vez, repassam para empresa de reciclagem. Já a emp18, vende as caixas de papelão dos produtos que compra. De acordo com os empresários entrevistados, estas experiências contribuem para um aproveitamento de todos os recursos da empresa. Vale ressaltar que algumas empresas não geravam resíduos e por isso não faziam gestão dos mesmos. Logo, não obtiveram pontuação alta neste item.

Já as empresas com inovações de processos ocasionais são: emp3 que faz a separação do seu lixo, mas segundo o empresário, a empresa responsável pela coleta do município não dá continuidade ao trabalho; a emp4 faz destinação dos plásticos a empresas de reciclagem e incineração das madeiras inutilizadas no curtume local; a emp6 adotou a prática do lixo seletivo, separando os materiais; e a emp8 passou a separar seu lixo e disponibilizá-lo para coleta seletiva da prefeitura, e ocorrem quinzenalmente.

\section{CONSIDERAÇÕES FINAIS}

Através dos resultados deste artigo, foi possível mapear quais as inovações de processos foram implementadas por MPEs do setor de serviços do Sertão do São Francisco e analisar como estas ações impactaram nos resultados destas organizações neste período de crise. Evidenciou-se que as inovações realizadas pelas empresas na variável processos englobam ações em benchmarking, reestruturação de departamentos, capacitação dos colaboradores, criação de estratégias para vender os produtos (já presentes no estoque há muito tempo), mapeamento dos processos, redução na quantidade de fornecedores, aumento também do quadro funcional, melhoria do layout na loja, terceirização do serviço de entrega, registro de desperdícios, aquisição de softwares gerenciais, gestão eletrônica de documentos, adequação a aspectos ecológicos, reaproveitamento da água da chuva e do ar-condicionado, separação do lixo e vendas das embalagens usadas. Estas ações estão em consonância com o que Bachmann; Destefani (2008), Mompean (2014), Teixeira et al (2014) acreditam ser a concentração das ações de inovação de processos.

Pode-se destacar que parte das empresas analisadas precisa se readaptar para criar condições para inovar, visto que apenas cinco empresas ( $25 \%$ da amostra) apresentaram grau médio médio de inovação de processos igual ou superior a 3,0. O mercado é instável e novas dificuldades podem surgir, como crises que possam tomar maiores proporções, tendo a possibilidade de se instalarem no mercado local ou no segmento de forma mais direta, e por isso o empresariado deve trabalhar com projeção de cenários e identificar oportunidades de mudanças.

Os resultados desta pesquisa podem prover um panorama às empresas de serviços de Petrolina no que diz respeito à inovação de processos. A pesquisa in loco possibilitou verificar que ainda existem empresários que optam por continuar com seus procedimentos arcaicos, do que buscar a melhoria contínua. Poucas empresas visitadas possuíam procedimentos operacionais padrão (POPs) e não havia documentação dos processos. Isto 
pode gerar mais entraves a longo prazo, como dificuldades na execução de tarefas, desconhecimento técnico dos funcionários sobre algumas rotinas, dentre outros.

Embora os resultados tenham apontado para a adoção de diversas inovações para as empresas, as inovações de maior abrangência (que geram diferenciações da empresa no mercado) foram pouco observadas. Esta realidade pode causar, a longo prazo, uma perda de competitividade em relação a outras empresas do mercado (como as localizadas em Juazeiro-BA, que faz divisa com Petrolina).

Por fim, vale ressaltar que a pesquisa metodologicamente tem suas limitações, pois descreve exclusivamente quais ações de processos foram realizadas pelas empresas no âmbito da inovação durante o período de crise. Logo, mediante os resultados obtidos, outros estudos mais aprofundados podem ser produzidos, como a análise do grau de inovação de tipos específicos de empreendimentos de serviços e quais as ações implementadas pelas empresas mais auxiliaram a manter a competitividade.

Além disto, a adoção dos procedimentos metodológicos utilizados nesse estudo pode auxiliar na avaliação do que indústrias (por exemplo) realizaram nesse período de crise. Ainda é possível averiguar em quais regiões a adoção de inovações surtiram mais efeitos positivos e quais foram estas inovações.

\section{REFERÊNCIAS}

BACHMANN, D. L. E DESTEFANI, J. H. Metodologia para estimar o grau das inovações nas MPE. 2008. Disponivel em: <http://www.bachmann.com.br/ website/documents/ArtigoGraudelnovacaonasMPE.pdf>. Acesso em: 17 abr. 2018.

BAUER, R. Gestão da mudança: caos e complexidade nas organizações. São Paulo: Atlas, 1999.

BESSANT, J.; TIDD, J. Inovação e empreendedorismo. Porto Alegre: Bookman, 2009.

BEZERRA. M. C. Investimento em Inovação em Períodos de Crise e Recessão em Empresas de Investigação e Desenvolvimento. 2010. Dissertação (Mestrado em Economia). Departamento de Economia e Gestão Universidade Lusófona de Humanidades e Tecnologias, Lisboa, 2010. Disponível em:

$<$ http://recil.grupolusofona.pt/bitstream/handle/ 10437/1372/Dissertacao\%2oMahely.pdf?sequence=1>. Acesso em: 17 abr. 2018.

BOTELHO, M. R. A.; CARRIJO, M. C.; KAMASAKI, G. Y. Inovações, pequenas empresas e interações com instituições de ensino/pesquisa em arranjos produtivos locais de setores de tecnologia avançada. Revista Brasileira de Inovação, v. 6, n. 2, p. 331-371, 2007. Disponível em:

<http://ocs.ige.unicamp.br/ojs/rbi/article/view/323>. Acesso em: 17 abr. 2018.

CERVI, E. Métodos quantitativos nas ciências sociais: uma abordagem alternativa ao fetichismo dos números e ao debate com qualitativas. In: AYRES, J. B. (Org.). Pesquisa Social: reflexões teóricas e metodológicas. Ponta Grossa: Toda Palavra Editora, 2009.p. 125-143.

CRUZ, R. O empreendedor no processo de inovação de pequenas empresas de software do Rio Grande do Sul. In: ENCONTRO DE ESTUDOS SOBRE EMPREENDEDORISMO E GESTÃO DE PEQUENAS EMPRESAS, 3., 2003, Brasília, DF. Anais.... Brasília, DF: ANENGEPE, 2003. Disponível em:

<http://www.anegepe.org.br/edicoesanteriores/brasilia/[35].pdf>. Acesso em: 17 abr. 2018.

DYER, J.; GREGERSEN, H.; CHRISTENSEN, C. The Innovator's DNA: Mastering the Five Skills of Disruptive Innovators. Boston: Harvard Business Review Press, 2011.

FERNANDES, F. Em 2015, quase triplicou a taxa de mortalidade de empresas no país. Diário do comércio e negócios. [2016]. Disponível em: <http://www.dcomercio.com.br/categoria/negocios >. Acesso em: 20 abr. 2017. 
FERREIRA, D. Inocrowd: os benefícios da inovação aberta para a competitividade Empresarial Brasileira. Revista Exame. 2016. Disponível em: <https://exame.abril.com.br/negocios/dino/inocrowd-os-beneficios-dainovacao-aberta-para-a-competitividade-empresarial-brasileira-dino8gog1828131/>. Acesso em: 8 dez. 2017.

GIL, A. C. Como elaborar projetos de pesquisa. 5. ed. São Paulo: Atlas, 2008.

GOVERNO DO ESTADO DE PERNAMBUCO. Dados gerais das empresas comerciais segundo a divisão de comercio do Pernambuco. 2017. Disponível em: <http://www.anuario.pe.gov.br/atividadeseconomicas/comercio-e-servicos >. Acesso em: 17 abr. 2018.

INSTITUTO BRASILEIRO DE GEOGRAFIA E ESTATÍSTICA (IBGE). Produto Interno Bruto do Brasil, 2015. Disponível em: <http://www.ibge.gov.br/home/estatistica/indicadores/pib/defaultcnt.shtm> Acesso em: 18 abr. 2017.

KNOX, S. The boardroom agenda: Developing the innovative organization. Corporate Governance, Bradford, UK, v. 2, n. 1, p. 27-36, 2002. Disponível em:

<https://www.emeraldinsight.com/doi/abs/10.1108/14720700210418698>. Acesso em: 10 abr. 2018.

LEITE, M. V. C.. Teoria da demanda Efetiva: Keynes, Kalecki e algumas implicações. In: III Encontro Internacional da AKB, São Paulo, 2010. Anais.... São Paulo: AKB, 2010. Disponível em: https://pt.scribd.com/document/266041901/Chiliatto-Leite-Marcos-v-Teorias-Da-Demanda-Efetiva-KeynesKalecki-e-Algumas-Implicacoes>. Acesso em: 10 abr. 2018.

MACHADO, D. D. P. N.; CARVALHO, L. C. Ambiente favorável ao desenvolvimento de inovações: proposição de um modelo de análise organizacional. Revista de Administração, São Paulo, v. 48, n. 3, p. 592-607, jul./set. 2013. Disponível em: <http://www.scielo.br/pdf/rausp/v48n3/15.pdf>. Acesso em: 10 abr. 2018.

MATTEI, L.; RUCINSKI, R. Impactos da crise econômica sobre a economia catarinense. Geosul, Florianópolis, v. 31, n. 62, p 337-366, jul./dez. 2016. Disponível em:

<https://periodicos.ufsc.br/index.php/geosul/article/view/2177-5230.2016v31n62p337/3261 0>. Acesso em: 10 abr. 2018.

MAXAMADUMAROVICH, U. A.; OBRENOVIC, B.; AMONBOYEV, M. Understanding the Innovation Concept. Revista de Inovação e Sustentabilidade, São Paulo, v. 3, n. 3, p. 19-26, 2012. Disponível em: <https://revistas.pucsp.br/index.php/risus/article/view/ 12631>. Acesso em: 20 abr. 2018.

MINAYO, M. C. S. (Org.). Pesquisa social: teoria, método e criatividade. 29. ed. Petrópolis, RJ: Vozes, 2010.

MOMPEAN, F. L. A inovação em processos: uma análise da dimensão processos no comércio varejista do Vale do Itajaí. Cadernos de Inovação em Pequenos Negócios: comércio [recurso eletrônico], Sebrae, CNPq. v. 2, n. 2, 2014 .

OLIVEIRA, M. F. S. et al. O impacto das práticas inovadoras de micro e pequenos empreendedores na prosperidade de seus negócios. Revista Capital Científico, v. 14, n. 3, jul./set. 2016. Disponível em: <https://revistas.unicentro.br/index.php/capitalcientifico/article/view/3929/3136>. Acesso em: 20 abr. 2018.

ORGANISATION FOR ECONOMIC CO-OPERATION AND DEVELOPMENT (OECD). Manual de Oslo. Oslo: OECD, 2005 .

PIERRY, L. I. Inovação como diferencial competitivo no mercado globalizado. Porto Alegre: [s.n.], 2001. POZABON, R. O.; PRATES, A. C. A crise no governo Dilma: enquadramentos propostos pela Revista Veja. Revista de Estudos da Comunicação, Curitiba, v. 17, n. 42, p. 04-22, jan./abr. 2016. Disponível em: <https://periodicos.pucpr.br/index.php/ estudosdecomunicacao/article/view/22538/21622>. Acesso em: 01 mar. 2018.

POZOBON, R. O.; PRATES, A. C.. A crise no governo Dilma: enquadramentos propostos pela Revista Veja. Revista de Estudos da Comunicação, Curitiba, v. 17, n. 42, p. 04-22, jan. /abr. 2016. Disponível em: 
$<$ https://periodicos.pucpr.br/index.php/ estudosdecomunicacao/article/view/22538/21622> Acesso em 17 abr. 2017.

PRADELLA. S.. Gestão de Processos: uma Metodologia Redesenhada para a Busca de Maior Eficiência e Eficácia Organizacional. Revista Gestão \& Tecnologia, Pedro Leopoldo, v. 13, n. 2, p. 94-121, maio/ago. 2013. Disponivel em: <http://revistagt.fpl.edu.br/get/article/view/486>. Acesso em: 01 mar. 2018.

REINA, Márcia. A importância de uma Gestão Estratégica para o Processo de Inovação nas Empresas. XI CONGRESSO NACIONAL DE EXCELÊNCIA EM GESTÃO. 13 e 14 de agosto de 2015, Rio de Janeiro, RJ. Disponivel em: http://www.inovarse.org/sites/default/files/T_15_105.pdf. Acesso em: 23 jan. 2016.

ROMAN. D. J. et al. Fatores de competitividade organizacional. Brazilian Business Review, Vitória, ES, v. 9, n. 1, Vitória-ES, jan./mar. 2012. Disponível em:

<http://www.bbronline.com.br/_novo/artigos.asp?sessao=ready\&cod_artigo=39>. Acesso em: 01 mar. 2018.

ROSA, O. Ações avançadas de ambiência inovador: O reflexo dos resultados no grau global de inovação. Caderno de Inovação em Pequenos Negócios, v. 3, n. 3, 2015. Brasília: Sebrae, 2015.

SCHERER, F. O.; CARLOMAGNO, M. S. Gestão da Inovação na Prática. 2. ed. São Paulo: Atlas, 2016.

SCHUMPETER, Joseph Alois. A teoria do desenvolvimento econômico. $2^{\text {a }}$ Ed. São Paulo; Nova Cultura, 1984.

SOUZA, G.; BARROS NETO, J.P. (Org.) Manual do Empreendedor: de Micro a pequenas empresas. Rio de Janeiro: Qualitymark, 2012.

SPEZAMIGLIO, B. S.; GALINA, S. V. R.; CALIA, R. C.. Competitividade, inovação e sustentabilidade: uma interrelação por meio da sistematização da literatura. REAd, Porto Alegre, v. 84, n. 2, p. 363-393, maio/ago. 2016. Disponível em <http://www.scielo.br/scielo.php?script=sci_arttext\&pid=S1413-

$23112016000200363 \&$ lng = en\&nrm=iso\&tlng=pt $>$ Acesso em 17 abr. 2017.

STRUCK, J. O que levou o Brasil à atual crise econômica? [2016]. Disponível em <http://p.dw.com/p/1/6zy $>$ Acesso em 17. abr. 2017.

TEIXEIRA, P. C. et al. Padronização e melhoria de processos produtivos em empresas de panificação: estudo múltiplos de caso. Production, v. 24, n. 2, p. 311-321, 2014. Disponivel em

<http://www.scielo.br/pdf/prod/v24n2/aop_1037-12.pdf> Acesso em 17. abr. 2017. 